\title{
PROGRAMA DE ARRANJOS PRODUTIVOS LOCAIS EM ALAGOAS: UM ESTUDO SOBRE AO APL DE OVINOCAPRINOCULTURA DE ALAGOAS $^{1}$
}

\author{
José Francisco Oliveira de Amorim \\ Professor da Faculdade de Economia, Administração e Contabilidade - FEAC/UFAL. \\ Maceió, AL, Brasil. \\ josefranciscoamorim@gmail.com \\ Maria Lucélia Felix Nunes \\ Bacharel em Ciências Econômicas - Campus do Sertão/UFAL. \\ Maceió, AL, Brasil. \\ lucelia.nunes.batalha@gmail.com \\ Alonso Barros da Silva Junior \\ Doutorando em Economia - PPGE/Universidade Federal da Bahia (UFBA) \\ Bahia, BA, Brasil. \\ jr.econo@hotmail.com
}

\section{Grupo de Trabalho: Desenvolvimento Rural, Territorial e Regional}

\begin{abstract}
Resumo - As diversas transformações ocorridas em meados do fim do século XX, mais precisamente em sua última década, impactaram não apenas a economia mundial, mas também a brasileira, como bem destaca Costa (2010) surgiu o forte interesse no crescente movimento das aglomerações de pequenas e médias empresas ocorridas no território nacional. Sendo assim, o termo APL passou a ser utilizado com maior frequência, determinando um espaço social, construído ao longo de um período, envolvendo atividade econômica, a partir da aglomeração de agentes, sejam estas similares ou relacionadas, interagindo dentro de um espaço delimitado pelo fluxo de bens e serviços, não apresentando fronteira geográfica. Diante disso, o presente artigo pretende realizar uma análise do APL de Ovinocaprinocultura do sertão alagoano, destacando seu perfil e peculiaridades, assim também como vantagens e dificuldades.
\end{abstract}

Palavras-chave: Desenvolvimento; Sertão alagoano; APL; Ovinocaprinocultura.

\section{PROGRAM OF LOCAL PRODUCTIVE ARRANGEMENTS IN ALAGOAS: A STUDY ON THE OVINOCAPRINOCULTURE APL OF ALAGOAS}

\begin{abstract}
The various changes that occurred in the mid-late twentieth century, more precisely in his last decade, impacting not only the global economy but also Brazil, as well as highlights Costa (2010) came the strong interest in the growing movement of agglomerations of small and mediumsized companies over the national territory. Thus, the term APL is now used with greater frequency, determining a social space, built over a period involving economic activity, from the agglomeration of agents, whether similar or related, interacting within an area bounded by flow of goods and services, showing no geographical border. Therefore, this article intends to conduct an analysis of APL Sheep and Goat Farming the backlands of Alagoas, highlighting your profile and peculiarities, as well as advantages and also difficulties.
\end{abstract}

Key words: Development; Backlands of Alagoas; APL; Sheep and goat farming.

\footnotetext{
${ }^{1}$ Artigo apresentado no XII Congresso da Sociedade Brasileira de Economia, Administração e Sociologia Rural (SOBER NORDESTE, 2017), realizado em Itabaiana - Sergipe.
} 


\section{INTRODUÇÃO}

Durante a última década do século XX tivemos diversas transformações que impactaram diretamente a economia brasileira. As regras do jogo mudaram, passou-se a pensar na descentralização da atividade produtiva; com a constituição de 1988, deu-se mais autonomia política e administrativo-financeira aos municípios.

Além disso, passou-se a pensar em território, no desenvolvimento por meio do apoio de ações de territorialização, com o crescente movimento de aglomerações de pequenas e médias empresas. Diante disso, surgiu o interesse no apoio a ações que pudessem dar força às aglomerações produtivas. Os Arranjos Produtivos Locais surgiram dessa iniciativa, de buscar atividades com potencial para o desenvolvimento de regiões com pouco potencial para desenvolvimento no modelo antigo.

Logo destacamos a região do Sertão Alagoano como uma dessas regiões, propícias para o desenvolvimento através da aglomeração de atividades produtivas, no caso aqui destacado, a ação de Ovinocaprinocultura, tendo origem como alternativa para a região, mas que atualmente possui 600 pessoas empregadas, 5 associações e 5 cooperativas com 517 participantes. Os produtos desenvolvidos também apresentam potencial para o desenvolvimento de outros negócios, como os sabonetes de leite de cabra e o artesanato a partir do couro dos ovinos.

Mesmo sendo uma atividade nova na região, destacamos que alguns frutos são colhidos, porém o impacto das ações do APL só poderá ser identificado em um período futuro, no mínimo em 10 anos, visto que agentes de apoio a pesquisa e fomento estão dando suporte, como é o caso da UFAL (instalação do Campus Sertão), Embrapa, o Sebrae que terá uma filial em Delmiro Gouveia (alto sertão alagoano), além das ações de apoio do governo.

Com isso, tivemos como objetivo principal de estudo: analisar o APL de ovinocaprinocultura do sertão alagoano. E por objetivos específicos de estudo: a) Identificar o perfil do APL; b) Verificar o volume e a comercialização do APL; c) Identificar vantagens e dificuldades do APL; d) Verificar perspectivas de investimento e gestão; e por último e) As relações de cooperação entre os atores do APL.

O presente artigo é dividido em seis etapas: posteriormente a essa, temos os aspectos teóricos, definindo a origem dos estudos de APL no Brasil e caracterizando os arranjos; na terceira etapa são apresentados os aspectos metodológicos; na quarta etapa é feita a análise dos dados obtidos; na quinta etapa do artigo é apresentada uma conclusão do estudo e por último as referências bibliográficas são apresentadas. 


\section{ASPECTOS TÉORICOS}

No presente tópico, apresentamos o referencial teórico que deu suporte ao estudo desenvolvido. $\mathrm{O}$ mesmo foi dividido em três partes: primeiramente, foram apresentadas informações sobre a origem dos estudos sobre APLs no Brasil; em um segundo momento, destacamos a caracterização dos APLs e por último destacou-se o processo de competitividade e desenvolvimento.

\section{A ORIGEM DOS ESTUDOS DE ARRANJOS PRODUTIVOS LOCAIS NO BRASIL}

As diversas transformações ocorridas em meados do fim do século XX, mais precisamente em sua última década, impactaram não apenas a economia mundial, mas também a brasileira, como bem destaca Costa (2010). Surgiu o forte interesse no crescente movimento das aglomerações de pequenas e médias empresas ocorridas no território nacional, influenciadas pelo sucesso de experiências ocorridas ao redor do globo, destes, podemos destacar as experiências das cidades japonesas e do Vale do Silício.

O interesse na observação dessas aglomerações contribuiu para o surgimento da verificação da importância de parques tecnológicos, polos de tecnologia e incubadoras de empresas, como uma tentativa de modernizar as ações desenvolvidas no território nacional.

Costa (2010) destaca ainda que estudos desenvolvidos em meados da década de 1990 passaram a influenciar a cabeça de formuladores de políticas, como Porter, com o conceito de Cluster e os Distritos Industriais Italianos. Dessa forma, tais estudos passaram a influenciar a economia brasileira, disseminando a importância da atuação em conjunto, preservando uma estrutura economicamente produtiva. Contudo, as experiências visualizadas no Brasil diferem um pouco das realidades internacionais, devido a formação cultural. Diante disso, surge a tentativa de contribuir com o fortalecimento das ações a serem desenvolvidas em conjunto dessas pequenas e médias empresas. Novamente utilizando argumentos do autor citado, Costa (2010) destaca que o termo APL surgiu como uma espécie de "guarda-chuva", visando abrigar uma ampla diversidade de fenômenos, porém com a finalidade de constituir um instrumento de política econômica.

Sendo assim, o termo APL passou a ser utilizado com maior frequência, determinando um espaço social, construído ao longo de um período, envolvendo atividade econômica, a partir da aglomeração de agentes, sejam estas similares ou relacionadas, interagindo dentro de um espaço delimitado pelo fluxo de bens e serviços, não apresentando fronteira geográfica. As atividades desses agentes, ocorrem de forma articulada, utilizando da coopetição (cooperação e competição), levando em conta a identidade do local onde os agentes desenvolvem suas atividades, a confiança, os fatores locais favoráveis ao desenvolvimento das ações e fator que possivelmente apresente

REVISTA ECONOMIA POLÍTICA DO DESENVOLVIMENTO $\quad$ Maceió - AL $\quad$ V.2 N.3. $\quad$ JUNHO/2015 $\quad$ P.43-56 Página-45


maior importância a habilidade de governança que a comunidade local possui.

Diante dessa informação, o foco na abordagem de APLs como forma de desenvolvimento vai além dos conceitos de distritos industriais e clusters, pois envolve a participação não apenas da empresa como conhecemos, mas também inclui a possibilidade da atuação de outros agentes, como é o caso dos agentes produtores além dos agentes institucionais, envolvendo ações de cunho produtivo e territorial.

Podemos assim destacar que os agentes envolvidos no APL atuam de forma institucionalizada, seja esta direta ou indireta, harmônica e interagem cooperando entre si, porém sem deixar de lado a competição. Nesse cenário o tamanho das empresas não apresenta tanta importância, elas podem variar de pequenos agentes com uma estrutura mínima (chegando a estrutura artesanal às vezes), até estruturas organizadas com divisão de trabalho e alto conhecimento tecnológico, derivado da cumulatividade de conhecimento ao longo da existência da empresa.

A concentração das empresas contribui com a eficiência de todos os participantes, visto que a especialização é puxada pelos elos mais fortes, o que estimula o desdobramento e a especialização dos agentes com menor força competitiva, obrigados a desenvolver-se para não ser retirados do mercado, afinal a competição existe dentro do Arranjo. Uma característica marcante é a confiança, a existência de tal fator dentro do Arranjo possibilita a criação de laços fortes, de associações, promovendo o acesso a competências que de forma individual poderiam não conseguir. Para Costa (2010) as competências oriundas dessas associações podem proporcionar eficiência, diferenciar os produtos no mercado, promover melhor qualidade tornando-se competitivo o agente atinge outro ponto de lucratividade.

Esse "estímulo" ao trabalho em conjunto favorece a minimização do custo de transação e intensifica o processo de desenvolvimento tecnológico, reforçando a competitividade do mercado local, gerando externalidades positivas aos participantes, gerando um clima sinérgico e expansivo de crescimento da atividade local e vantagens competitivas fortes, por meio da dinâmica entre os agentes, essa dinâmica permite o fortalecimento do Arranjo de forma endógena, obtendo maior sucesso em suas ações. Os agentes que atuam como âncora para o Arranjo ganham com a redução do custo, aproveitando das especialidades externas as suas ações, os insumos para a atividade produtiva são garantidos de forma adequada, implementando técnicas modernas e eficientes.

Por outro lado, os agentes institucionais também ganham com essa articulação, afinal desenvolve-se maior geração de pesquisa e conhecimento cientifico, além disso, permite-se maior integração entre Universidade, Centros de Pesquisa e empresariado local. A mão de obra é melhor capacitada, ocorrem melhorias no processo de capacitação, 
melhoria das técnicas gerenciais e organizacionais, maior qualidade, proporcionando desenvolvimento na infraestrutura regional.

E, por conseguinte, o governo local ganha com a promoção e o desenvolvimento econômico de sua região, incrementando o aumento do volume de captação de recursos advindos das ações de mercado.

\section{CARACTERIZANDO OS ARRANJOS PRODUTIVOS LOCAIS}

As pequenas e médias empresas passam por diversas limitações, desde o processo de entrada no mercado até o processo de competição por custo, levando em consideração características locais. Diante disso, necessitam utilizar de estratégias flexíveis, que permitam maior cooperação e troca de informações.

Seguindo essa fragilidade das pequenas empresas, Cassarotto e Pires (2001) evidenciam que essas empresas podem optar por duas alternativas: fornecer produtos para grandes empresas ou participar de redes flexíveis de pequenas empresas. Britto (2000) afirma ainda que os Arranjos Produtivos Locais podem ser definidos por concentrações geográficas de atividades econômicas inter-relacionadas ou interdependentes.

A Redesist desenvolveu o conceito de APL (Arranjo Produtivo Local) como aglomerações territoriais de agentes econômicos e políticos-sociais, representando vínculos que envolvem a interação de empresas. Lastres e Cassiolato (2003) destacam que tais vínculos podem ser desde atividades produtoras de bens e/ou serviços finais até fornecedoras de insumos e equipamentos, incluindo instituições. Essas outras instituições podem apresentar natureza pública ou privada, formando e capacitando os recursos humanos existentes, ou mesmo servindo como articuladora entre os agentes do Arranjo.

Aquino e Bresciani (2005) destacam a presença de instituições de suporte aos APLs, como entidades de cunho político, pesquisa e desenvolvimento, universidades e entidades para capacitação.

Em seus estudos, Lastres e Cassiolato (2003) argumentam que os APLs resultam da caracterização seguindo a seguinte lógica: dimensão territorial; diversidade de atores e atividades econômicas; conhecimento tácito, inovação e aprendizado, governança e grau de enraizamento das ações. Partindo dos argumentos aqui apresentados, podemos destacar algumas características para determinar a existências dos APLs: a) a quantidade de agentes participantes, tendo por finalidade o desenvolvimento de uma atividade em comum; b) a identificação de um espaço geográfico, onde as atividades são desenvolvidas; c) a participação de agentes de pesquisa e desenvolvimento, promovendo o desenvolvimento tecnológico; d) Instituições que possam fornecer crédito aos participantes; e por último, a cooperação entre as empresas/agentes participantes do Arranjo.

Com o avanço das ações, os Arranjos evoluem e consolidam seu espaço no mercado, 
estabelecendo diretrizes necessárias a sua continuidade, o agente governamental favorece o desenvolvimento por meio da estruturação e apoio as atividades desenvolvidas, afinal, os agentes inicialmente necessitam de apoio para posteriormente caminhar com as próprias pernas.

Em seu trabalho, Machado (2003) destaca que a evolução dos APLs ocorre de maneira equivalente a dos distritos industriais, através de quatros fases, onde são apresentadas as principais características de cada fase no quadro abaixo:

Quadro 01: Desenvolvimento dos Arranjos Produtivos Locais, Machado, 2003.

\begin{tabular}{|c|l|}
\hline FASES & \multicolumn{1}{|c|}{ CARACTERÍSTICAS } \\
\hline Nascimento & $\begin{array}{l}\text { Existe a adoção de inovações revolucionárias com economia de escalas de forma } \\
\text { significativa. Não existe instalação de rede de fornecedores. A competição é obtida a } \\
\text { partir do custo, sem preocupação com a qualidade e a cooperação é de caráter informal. }\end{array}$ \\
\hline Crescimento & $\begin{array}{l}\text { Os setores são atraídos pelo APL. A demanda possibilita aos fornecedores aumentarem } \\
\text { a produção, ocorre ainda a especialização de categorias profissionais, o conhecimento é } \\
\text { trocado a partir de processos informais, surgindo spin-offs(empregados deixam } \\
\text { empresas para abrirem seus negócios). Competição construída por preço, a governança } \\
\text { se estabelece no elo da cadeia produtiva. }\end{array}$ \\
\hline Maturidade & $\begin{array}{l}\text { A estagnação acirra a competição inter-empresarial, reduzindo as margens de } \\
\text { comercialização, isso faz com que as empresas líderes busquem novos mercados, provocando } \\
\text { o aumento dos custos de transação. Diante disso, a competição passa a ser baseada em } \\
\text { qualidade e flexibilidade ou marca. Surgem oportunidades de cooperação horizontal na } \\
\text { comercialização do produto final. O processo produtivo torna-se mais codificado. }\end{array}$ \\
\hline $\begin{array}{c}\text { Pós- } \\
\text { maturidade }\end{array}$ & $\begin{array}{l}\text { Redução da força de atração de aglomerados industriais. Os agentes passam a enfrentar a } \\
\text { competição de outras localidades, o conhecimento cumulativo possibilita o surgimento de } \\
\text { outros negócios com alto valor agregado, dando impulso à atividade econômica local. }\end{array}$ \\
\hline
\end{tabular}

Fonte: Machado, 2003.

Porém antes de verificar o desenvolvimento e consolidação dos APLs, torna-se essencial a compreensão da realidade local, compreender características culturais, principalmente na atual sociedade da informação e conhecimento. Isso permite desenvolver a necessária compreensão das transformações que podem ocorrer, visualizando como se estruturam e como se movimentam.

Outra necessidade para seu desenvolvimento está ligada ao envolvimento de agentes no processo, agentes que conhecem a realidade local, que acompanharam o desenvolvimento das atividades e das ações desenvolvidas na localidade, melhor enfatizando, as instituições públicas e de fomento. E outro fator é a participação das instituições de pesquisas, com essas ações desenvolvidas, podemos destacar que quanto maior for o grau de integração e envolvimento dos participantes, maiores serão os resultados obtidos, afinal as estratégias para o desenvolvimento dependerão da confiança existente. 


\section{ARRANJOS PRODUTIVOS LOCAIS: COMPETITIVIDADE E DESENVOLVIMENTO}

A nova sociedade do conhecimento aponta para a necessidade de novos desafios, exigindo uma nova forma de pensar e agir. Isso influencia no processo competitivo e progresso econômico da localidade. Devido a isso, é necessário o desenvolvimento e capacitação da mão de obra.

As empresas/agentes não devem atuar de forma isolada, afinal, não são isolados, uma vez que fazem parte de uma rede. A atuação em conjunto permite o desenvolvimento de inovações tecnológicas, resultantes da aprendizagem cumulativa e em conjunto. Esse processo de inovação é distinto do ocorrido em grandes organizações, afinal a dinâmica é outra.

Evidenciamos, ainda, que a inovação organizacional passa a ser fundamental para a formação e constituição, a depender da dinâmica que estão inseridas. Em seu trabalho, Cassiolato e Lastres (1999) tentam compreender a formação e desenvolvimento dos Arranjos Produtivos Locais através da ótica evolucionista, por meio da mudança tecnológica e da inovação. Utilizando de argumentos de Porter (1999), o mesmo evidencia que muitas vantagens competitivas dependem de fatores locais, desta forma as concentrações geográficas passam a apresentar crucial importância no desenvolvimento e crescimento de regiões. Cassiolato e Latres (2003) também já apresentaram esse mesmo sentimento, afinal, a competitividade é importante para o crescimento das organizações.

E o conceito de competitividade tornou-se bastante difundido, o próprio desenvolvimento regional passa a ser visto como saída para a busca na resolução de problemas territoriais. Lastres e Cassiolato (2003) evidenciam que a ideia de APL permite o auxílio na superação de problemas conhecidos e não superados com as abordagens tradicionais, e que não podemos focalizar apenas nas unidades produtivas individuais ou setoriais. Pois devemos considerar as especificidades locais do ambiente em que os agentes estão inseridos, e ainda, não se restringindo a um único setor. Ou seja, as pequenas e médias empresas não devem e não podem ficar isoladas, pois essa ação promove a criação de limitações e dificuldade no seu desenvolvimento, promovendo a não criação de vantagens competitivas.

Por isso, os APLs devem ser apoiados por instituições públicas e privados; de cunho financeiro, pesquisa e desenvolvimento, e atuação governamental. Cassaroto e Pires (2001) já evidenciavam essa preocupação, destacando que os APLs surgem como alternativa para o desenvolvimento, além da ampliação do vetor da regionalização social, permitindo a diminuição das desigualdades regionais. 


\section{ASPECTOS METODOLÓGICOS}

Considerando as linhas de pesquisa e estudos desenvolvidos, Selltizetalli (1987) destacam que a metodologia adotada em um estudo depende de sua natureza, podendo ser classificado como: exploratórios, descritivos e causais.

O nosso estudo pode ser considerado descritivo, pois nos pautamos em dados secundários, obtidos por meio do acompanhamento de ações da Superintendência de Desenvolvimento Regional e Setorial (Suder), ligada a Secretaria de Estado do Planejamento e do Desenvolvimento Econômico de Alagoas (Seplande). A Suder formula, articula e realiza ações visando à promoção do desenvolvimento regional e setorial, abrigando ações dos Programas: a) Arranjos Produtivos Locais; b) Artesanato Brasileiro; c) Territórios da Cidadania; e d) Cadeias Produtivas.

A metodologia aqui desenvolvida foi desenvolvida em três etapas: Na primeira etapa foi realizada uma caracterização do APL, segundo a abordagem conceitual da Redesist. No segundo momento, foram destacadas as principais informações do APL, com base nas informações de estudos da Redesist, envolvendo desde a própria caracterização das informações a obtenção de informações de volume, comercialização e cooperação. Na terceira etapa buscou-se avaliar de forma qualitativa e quantitativa as informações obtidas.

Os dados obtidos e analisados são de natureza quantitativa e qualitativa, contudo, a análise preponderante ocorreu de forma qualitativa com base na análise dos dados obtidos. Para isso, dividimos a análise em pontos específicos, onde cada ponto está ligado a um objetivo específico do estudo desenvolvido.

\section{ANÁLISE DE RESULTADOS}

O presente tópico desse trabalho possui por objetivo, realizar uma análise dos dados obtidos de forma precisa. Inicialmente destacamos o APL de Ovinocaprinocultura do Sertão de Alagoas e posteriormente, analisamos os pontos específicos do Arranjo.

\section{O APL DE OVINOCAPRINOCULTURA DE ALAGOAS}

O APL de Ovinocaprinocultura de Alagoas consiste em uma iniciativa do PPA de Alagoas, tendo origem durante o Plano de 2004 a 2007. O programa contou com apoio técnico do Sebrae, como principais benefícios do programa buscou-se a maior interação e cooperação entre produtores e demais participantes, redução dos custos dos participantes do APL, maior agilidade e flexibilidade e melhoria da qualidade dos serviços.

O objetivo inicial do programa foi promover a melhoria e a inclusão social de famílias

$\begin{array}{lllll}\text { REVISTA ECONOMIA POLÍTICA DO DESENVOLVIMENTO } & \text { Maceió - AL } & \text { V.2 N.3. } & \text { JUNHO/2015 } & \text { P.43-56 Página-50 }\end{array}$


que operam em pequenos negócios, e promover o desenvolvimento e parcerias, buscando especializar e buscar investimentos fazendo com que os atores presentes no território possam ser responsáveis pelo seu desenvolvimento. Abaixo é apresentado o Mapa do APL.

Figura 01: APL de Ovinocaprinocultura de Alagoas.

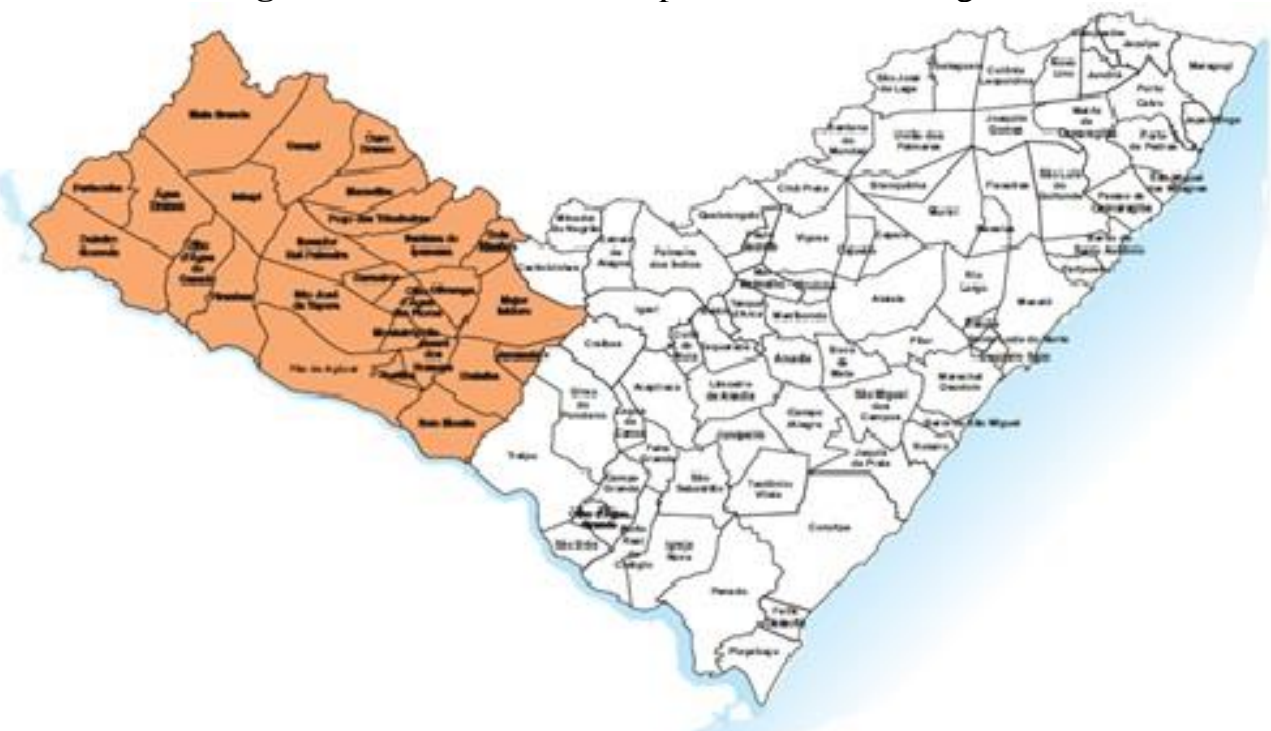

Fonte: Lustosa et alli, 2010.

\section{PERFIL DO APL}

Atualmente, o APL de Ovinocaprinocultura conta com a participação de 6 (seis) associações, com 106 (cento e seis) associados, e 5 (cinco) cooperativas, com 517 (quinhentos e dezessete) participantes da cooperativa, possui também um grupo gestor, comitê e câmara setorial. Os agentes participantes classificam-se como micro, pequeno e de médio porte.

Conforme podemos verificar no quadro abaixo, o APL possui mais de 800 pessoas diretamente envolvidas, com 600 pessoas empregadas.

Quadro 02: Perfil do APL.

\begin{tabular}{|c|c|}
\hline INFORMAÇÕES & VALORES \\
\hline $\mathrm{N}^{\mathbf{o}}$ de Pessoas Ocupadas & 817 \\
\hline $\mathrm{N}^{\mathbf{o}}$ de Pessoas Empregadas & 600 \\
\hline Renda dos Produtores ou (estabelecimentos) & 82,66 \\
\hline
\end{tabular}

Fonte: Suder, 2014.

\section{VOLUME E COMERCIALIZAÇÃO DE MERCADORIAS DO APL}

A renda média dos produtores deve-se ao território, o próprio Estado de Alagoas possui indicadores econômicos e sociais que sempre o colocam nas últimas posições no ranking nacional, e a região do Sertão alagoano apresenta valores menores ainda que a média. 
O valor da produção chega a valores de $\mathrm{R} \$ 40.020,00$, aproximadamente a comercialização chega a valores de $\mathrm{R} \$ 39.400,00$. Atualmente, a captação de recursos chega a valores de $\mathrm{R} \$$ $10.000,00$ com investimentos realizados de $\mathrm{R} \$ 22.000,00$. O quadro abaixo apresenta o volume de produção, comercialização e valores comercializados por produto desenvolvido.

Quadro 03: Volume e comercialização de mercadorias, Suder, 2014.

\begin{tabular}{|c|c|c|}
\hline $\begin{array}{l}\text { Volume de Produção (Quant.)/ } \\
\text { Produtos por Tipo }\end{array}$ & $\begin{array}{l}\text { Comercialização } \\
\text { (Quant). }\end{array}$ & $\begin{array}{l}\text { Valor da comercialização } \\
\text { (R\$) }\end{array}$ \\
\hline Leite caprino (3.500- L) & $3.000-\mathrm{L}$ & $7.800,00$ \\
\hline Animais vivos (alto sertão) & $3700 \mathrm{~kg}$ & $37.000,00$ \\
\hline Sabonetes & $800 \mathrm{unds}$ & $3.200,00$ \\
\hline Artesanato couro & $40 \mathrm{unds}$ & $1.200,00$ \\
\hline
\end{tabular}

Fonte: Suder, 2014.

Em relação ao faturamento do APL, foi verificado que em animais vendidos vivos no Alto Sertão durante os meses de novembro 2011 foi de R $27.920,00$, em dezembro de $2011 \mathrm{R} \$$ 66.769,00 e em janeiro de $2012 \mathrm{R} \$ 91.394 .000,00$.

Em relação ao faturamento do leite caprino formal, uma das cooperativas destacou que em 2012 o faturamento chegou a $\mathrm{R} \$ 36.000,00$ em litros (9000 litros de leite caprino por ano 2012) e em 2013 o valor chegou a $\mathrm{R} \$ 162.000,00$ de com vendas para o mercado regional (cerca de 54.000 litros de leite de cabra). A fábrica de cosméticos a base de leite de cabra, alcançou o faturamento de $\mathrm{R} \$ 56.000,00 \mathrm{em} 2012$ e $\mathrm{R} \$ 57.400,00 \mathrm{em}$ 2013, produziu aproximadamente em 2012 um total de 14.000 sabonetes, e em 2013 57.400,00.

Quanto ao couro, em 2012 o faturamento chegou a R\$22.000,00 e em 2013 R\$ 25.000,00. Percebemos que estão ocorrendo alguns avanços, mesmo que pequenos, mas o desenvolvimento do ambiente ocorrerá com o tempo.

\section{VANTAGENS E DESVANTAGENS DO APL}

Devido a sua formação, a partir da ocupação de fazendas de gado bovino e de cultivo, e beneficiamento da industrialização do algodão. Porém as atividades produtivas continuaram levando a população a buscar novas alternativas para sua permanência no meio rural.

Diante disso, a atividade de ovinocaprinocultura tornou-se a alternativa escolhida. Seguindo o atual ambiente, destacamos algumas vantagens e dificuldades do APL.

Em relação as dificuldade, podemos destacar:

- Alto custo de produção devido a elevação no preço dos insumos, e redução da margem de lucro do produtor;

- Dificuldades de acesso a meios de produção, conservação e armazenamento de alimentos para o rebanho em quantidade suficiente;

- Dificuldade de acesso ao crédito e falta de mão-de-obra qualificada; 
- Baixo nível de conhecimento técnico, gerencial e de práticas de produção ambientalmente corretas e Incompatibilidade da formação de recursos humanos com a realidade e as necessidades da região semi-árida;

- Baixo nível de organização dos produtores e Resistência às inovações tecnológicas;

- Descontinuidade na orientação e acompanhamento técnico, principalmente sob o ponto de vista da aplicação dos conhecimentos adquiridos;

- Limitação do mercado para o leite caprino, assim como a falta de estrutura e ou de organização da comercialização;

\begin{tabular}{|c|l|}
\hline \multicolumn{2}{|c|}{ Quadro 04: Vantagens do APL } \\
\hline Tipo de Vantagem & \multicolumn{1}{c|}{ Vantagens } \\
\hline Cultural & $\begin{array}{l}\text { A ovinocaprinocultura é atividade econômica tradicional, em } \\
\text { especial na região semi-árida; }\end{array}$ \\
\hline Recursos Naturais & $\begin{array}{l}\text { Avegetação nativa (caatinga) é rica em espécies forrageiras de } \\
\text { alto valor nutritivo - protéico e energético, constituindo } \\
\text { importante fonte de alimento para os rebanhos ovino e caprino; }\end{array}$ \\
\hline Mercado & $\begin{array}{l}\text { Carência de produtos da ovinocaprinocultura nos mercados } \\
\text { regional e nacional; }\end{array}$ \\
\hline
\end{tabular}

Fonte: Suder, 2014.

\section{PERSPECTIVA DOS INVESTIMENTOS PARA OS PRÓXIMOS ANOS}

Quanto a gestão do APL, foi contratada uma empresa especializada em desenvolvimento territorial, com a finalidade de atuar junto ao APL. O objetivo consiste no incremento da competitividade dos agentes participantes do APL, além da articulação institucional para o desenvolvimento sócio-econômico-ambiental do estado de Alagoas.

Os investimentos maiores estão sendo realizado através de Programa Federal e Estadual de melhoria genética do rebanho de ovinos e caprinos, com continuidade em 2014.

Além disso, estão sendo construídas 100 casas rurais no território do Alto Sertão aos sócios da Coofadel inseridos no projeto Bioma Caatinga/Ministério das Cidades e FBB, com finalização para junho de 2015.

O mais importante projeto de inovação no APL ovinocaprino é a Rastreabilidade financiado pelo BID e pela Desenvolve beneficiando os sócios da Cooperativa Coofadel. O objetivo da rastreabilidade é permitir, rapidamente, o resgate do histórico do produto e de seu processo de produção, do campo ao prato, atuando como mecanismo fundamental na segurança alimentar da população.

A rastreabilidade consiste no acompanhamento e registro de todos os eventos, ocorrências, manejos, transferências e movimentações ocorridas durante sua vida, desde o momento de seu nascimento ou identificação até seu abate ou morte, através de notificações em cadernos de campo, realizado pelos produtores e acompanhados pelos técnicos que prestam assistência.

O conceito da rastreabilidade propõe transparência, honestidade e permanente diálogo 
entre as partes envolvidas na produção, visando à satisfação do consumidor cada vez mais exigente e o estímulo para aqueles que participam do processo. Componentes do sistema:

- Padronização de procedimentos de Campo;

- Sistema de histórico individual e de propriedade;

- Padronização de procedimentos na Indústria.

\section{RELAÇÕES DE COOPERAÇÃO ENTRE OS ATORES DO ARRANJO PRODUTIVO}

Desde 2012, o governo de Alagoas por meio da Secretaria de Estado do Planejamento e do Desenvolvimento Econômico em parceria com a Agência de Desenvolvimento de Alagoas Desenvolve e o SEBRAE, Coordena o Programa de Desenvolvimento dos Arranjos Produtivos Locais - PAPL, do qual o APL é integrante e tem o apoio das seguintes instituições:

Quadro 05: Relações de cooperação com atores do arranjo produtivo, Suder, 2014.

\begin{tabular}{|c|l|}
\hline TIPO & \multicolumn{1}{c|}{ INSTITUIÇÕES } \\
\hline Ensino e Pesquisa & UFAL, IFAL, Uneal, Cesmac e EMBRAPA \\
\hline Fomento & $\begin{array}{l}\text { CODEVASF, Ministérios da Integração Regional, Desenvolvimento } \\
\text { Social, Desenvolvimento Agrário, FAPEAL. Participam também as } \\
\text { Secretarias de Estado da Agricultura e do Desenvolvimento Agrário, } \\
\text { Ciências e Tecnologia e do Trabalho e Renda }\end{array}$ \\
\hline Instituições financeiras & Banco do Brasil, Caixa Econômica Federal e Banco do Nordeste; \\
\hline Representação & Câmara Setorial e CIATs; \\
\hline Outras & $\begin{array}{l}\text { Instituto de Meio Ambiente, SENAR, SENAI, SENAC, CONAB, } \\
\text { Fundação Banco do Brasil, FAEAL, FAPEAL, IDERAL, Instituto } \\
\text { Xingó, CHESF e Prefeituras Municipais. }\end{array}$ \\
\hline
\end{tabular}

Fonte: Suder, 2014.

A força sinérgica da integração institucional atuando por gestão compartilhada sobre projetos e atividades produtivas deverão ter capacidade de elevar o padrão de vida e fazer circular riquezas, com a preocupação constante na sustentabilidade territorial.

Em relação aos programas específicos desenvolvidos por diferentes âmbitos de governo, estão ligados ao APLo Programa Alagoas Mais Ovinos; o Projeto de Rastreabilidade de Ovinos e Caprinos; o Programa Bioca Caatinga - DRS; o Fortalecimento da cadeia produtiva da ovinocaprinocultura no estado de Alagoas para potencializar o desenvolvimento local e a geração de trabalho e renda; o Programa Rota do Cordeiro; o Programa Balde Cheio; o Programa Centro de Integrações; e o Centro de Convivência com o Semi-Árido de Xingó.

\section{CONCLUSÃO}

Durante a década de 1990, muitas transformações ocorreram na realidade econômica brasileira, desde mudanças e reformas políticas industriais e tecnológicas a reformas estruturais. Tais transformações possibilitaram investimentos necessários para a integração 
das economias locais ao processo de globalização.

As decisões de investimento passaram a ser tomadas pelas grandes empresas, que aproveitaram da abertura comercial para entrar no mercado brasileiro, essas empresas passaram a promover mudanças estruturais, contudo, satisfazendo as suas necessidades.

Diante disso, tornou-se mais difícil para as micro e pequenas empresas manterem-se no mercado, devido a forte concorrência com grandes empresa e grupos econômicos fortes. Diversos impactos foram sentidos por esses agentes, destacamos que a importação de produtos de outros países quebrou a cadeia existente, formada por pequenas empresas que serviam como fornecedoras. Por sua vez, as empresas locais apresentaram baixas taxas de crescimento, necessitando de suporte para suas atividades.

O suporte dado as micro e pequenas empresas através do surgimento dos Arranjos Produtivos Locais, potencializaram a manutenção das empresas e o nascimento e maturidade de outros negócios, dando suporte a atividades produtivas e fortalecendo as regiões pouco assistidas.

O presente artigo buscou analisar o Arranjo Produtivo Local de Ovinocaprinocultura de Alagoas, destacando seu perfil, volume e comercialização e suas funcionalidades na região do Sertão alagoano.

Através das informações obtidas, podemos verificar que o Arranjo ainda apresenta fragilidades, com nível de confiança baixo entre os agentes participantes, sendo necessária a atuação do comitê gestor e câmara setorial.

Verifica-se ainda, que o papel da Suder é bastante importante para a manutenção desse Arranjo. Verificamos algumas vantagens do Arranjo, como a própria atividade, tendo surgido como alternativa, mas verifica-se que a mesma possui alto potencial para o desenvolvimento da região; os recursos naturais, por meio das espécies forrageiras de alto valor nutritivo para os animais; o mercado e produtos, por meio dos produtos da região. Entretanto, verificamos algumas dificuldades: como o alto custo, dificuldades de acesso a meios de produção e ao crédito, problemas com a mão de obra e qualificação, baixo nível de organização dos agentes e a limitação do mercado aos produtos.

Entretanto, mesmo diante das dificuldades encontradas, percebemos que o Arranjo possui alto potencial para o desenvolvimento, devido ao crescimento (mesmo que lento) do volume de comercialização, e em um futuro próximo espera-se que a região possa desenvolver-se por meio da atividade local, permitindo o avanço do conhecimento tecnológico e aumento das oportunidades de negócio. 


\section{REFERÊNCIAS BIBLIOGRÁFICAS}

AQUINO, André Luiz de.; BRESCIANI, Luis Paulo. Arranjos produtivos locais:uma abordagem conceitual. Organizações em contexto, Ano 1, n. 2, dezembro de 2005

CASTRO, A. M. G. Cadeia produtiva e prospecção tecnológica como ferramentas para a gestão da competitividade. Brasília: Embrapa, 2003.

COSTA. Eduardo José Monteiro da. Arranjos Produtivos Locais, Políticas públicas,e desenvolvimento regional. Brasília, 2010.

KIDDER, L.H. Trad: Maria Martha H D’Oliveira e Miriam M Del Rey. São Paulo: EPU, 1987.

LASTRES, H.; CASSIOLATO et al. Globalização e inovação localizada. Rio de Janeiro: UFRJ, 1998.

LASTRES, Helena M.M. Arranjos e sistemas produtivos e inovativos locais: contribuições para uma nova política de desenvolvimento industrial e tecnológico.Centro de Gestão e Estudos Estratégicos (CGEE). Rio de Janeiro, 7 de junho de 2007.

LASTRES, H., CASSIOLATO, J., LEMOS, C., MALDONADO J. E VARGAS,M.. Arranjos Locais e Capacidade Inovativa em Contexto Crescentemente Globalizado, Relatório do projeto de pesquisa apoiado pela Diretoria de Políticas Públicas do IPEA, IE/UFRJ,Rio de Janeiro, 1998.

LUSTOSA, Maria Cecília J. ; ROSARIO, F. J. P. ; COSTA, M. J. P. ; NUNES, M. C. L. ; SILVA, G. D. C. Síntese dos resultados, conclusões e recomendações das políticas de apoio aos arranjos produtivos locais - Alagoas. 2010. Nota Técnica nº 07, BNDES, Fortaleza, 2010.

MACHADO, Solange Aparecida. Dinâmica de arranjos produtivos locais: um estudo de caso em Santa Gertrudes, a nova capital da cerâmica brasileira. 2003. 162 f.. Tese (Doutorado em Engenharia da Produção) - Escola Politécnica. Universidade São Paulo, São Paulo, 2003.

PORTER, M. E. Clusters and the New Economics of Competition. Cambridge, MA: Harvard Business School Press, 1998.

PORTER, Michael. E. Competição on competition estratégias competitivas essências. Rio de Janeiro: Campus, 1999.

PORTER, Michael. E. A vantagem competitiva das nações. Rio de Janeiro: Campus, 1993.

SELLTIZ et alli. Métodos de Pesquisa nas relações sociais: medidas na pesquisa social. (Org.)

SUDER. Superintendência de Desenvolvimento Regional e Setorial. Maceió, 2014. Disponível em: $<$ http://www.seplande.al.gov.br/acesso-a-informacao/lista-de-pastas/perguntasfrequentes/superintendencia-de-desenvolvimento-regional-e-setorial/superintendencia-dedesenvolvimento-regional-e-setorial-1> Acesso em: 20 de Set. 2014. 